\title{
Taxi, de Jafar Panahi: o realizador diante do dispositivo fílmico
}

\author{
Renata Ferraz*
}

\author{
Taxi (Irão, 2015, 82 minutos) \\ Realização: Jafar Panahi. \\ Argumento: Jafar Panahi. \\ Elenco: Jafar Panahi. \\ Produção: Jafar Panahi. \\ Imagem: Jafar Panahi. \\ Som: Jafar Panahi.
}

Com este texto busca-se a análise da longa metragem Taxi (2015), o mais recente filme do realizador iraniano Jafar Panahi, representante de um certo tipo de cinema contemporâneo que vem buscando caminhos inusitados no que diz respeito a criação de filmes autobiográficos. Aqui, o modo de autorrepresentação invoca uma fusão entre a esfera social e a privada, sendo que a subjetividade do realizador é construída e alterada juntamente com a narrativa fílmica. Embora existam experiências autobiográficas no cinema desde a década de quarenta do século passado, como é o caso de Meshes of the Afternoon (1943), protagonizado por Maya Deren - investigação sobre os estados de inconsciência da mente da protagonista-realizadora -, ou ainda os diários fílmicos de Jonas Mekas (1969), não se pode deixar de observar que Jafar Panahi oferta importantes pistas para a compreensão de um fenômeno que tem ganhado significativo número de adeptos na produção cinematográfica da contemporaneidade. Tal fenômeno pauta-se nas dinâmicas geradas a partir da relação entre a subjetividade do realizador e aquilo que o constitui, entre o dentro e o fora do enquadramento dos planos, entre o diálogo próprio da narrativa fílmica, a vida pessoal do realizador e o seu vínculo com outras esferas sociais.

Tal estudo começa, pois, pelo epílogo, pela observação dos créditos finais do filme, onde todas as funções são direcionadas para um único homem: Jafar Panahi. Se o encargo atribuído ao genérico fílmico tem sido o de indicar as

* Doutoranda. Universidade de Lisboa, Faculdade de Letras, Faculdade de Belas Artes e ESTC - Escola Superior de Teatro e Cinema. Doutoramento em Artes Performativas e da Imagem em Movimento. 1649-004, Lisboa, Portugal. Bolsista da CAPES, Ministério da Educação do Brasil, Brasília - DF 70040-020. Email: renataferraz.info@gmail.com 
pessoas e as instituições participantes na empreitada cinematográfica, indicação esta que foi ganhando maior importância na medida em que os atores e os realizadores passaram a angariar o estatuto de celebridades internacionais, em Taxi, o que se observa é um suspeito solilóquio protagonizado pelo realizador. Tal creditação soberana poderia ter dois significados: o coroamento derradeiro do realizador-autor ou, então, uma restrição qualquer que justificasse o anonimato dos outros criadores. Numa tentativa de esclarecer esse enigma, as palavras do próprio realizador nos créditos finais do filme informa sobre o fato do Ministério da Orientação Islâmica só aprovar filmes distribuíveis ${ }^{1}$ e, portanto, com grande pesar, não poderia nomear as pessoas que o auxiliaram na criação da longa metragem.

Faz cinco anos que os meios de comunicação ocidentais reiteram que Panahi vive sob o efeito de uma ordem judicial que instituiu a sua prisão domiciliar por seis anos e proibiu-o de exercer a sua profissão por vinte, acusado de fazer um filme sem autorização do governo e se opor ao mesmo. Proteger as pessoas que o auxiliaram na criação de Táxi de uma possível punição como a sua, seria, pois, o fator responsável por tal ficha técnica.

Longe de fomentar a massa de vozes que quer encontrar no realizador iraniano a figura do herói que luta contra o mostrengo islâmico dentro do próprio labirinto onde nasceu e cresceu, enquanto os festivais internacionais de cinema seguram o fio de lã, prontos a puxá-lo assim que a tarefa fílmica estiver sido realizada, o que interessa aqui é refletir sobre as relações que Panahi vem estabelecendo com as circunstâncias que constituem a sua vida nos últimos cinco anos e como este diálogo tem atravessado a sua produção mais recente. Afinal, não é segredo para ninguém que Taxi é o terceiro filme que Panahi realiza após a sua condenação. Portanto, longe de ser vítima de um sistema que o condena, a condição que ele vive hoje juntamente com a ironia já presente nos trabalhos anteriores são dois dos maiores responsáveis pela produção corrente do realizador.

Dito isso, não é possível desarticular o trabalho de Jafar Panahi e a sua vida. Se numa observação ligeira, o primeiro filme, depois de ocorrida a sentença, This is not a film (Panahi, 2011), continha mais elementos biográficos que ficcionais, já que partia da documentação de sua vida quotidiana em regime de prisão domiciliar, não se pode deixar de considerar que Taxi é igualmente contaminado pelos traços biográficos do realizador e pelos conflitos reais de sua prática artística.

1. A palavra distribuível é usada aqui como uma alusão à conversa que o realizador tem com a sobrinha em uma das cenas do filme, quando a menina diz que na escola tem aprendido as regras para fazer filmes distribuíveis. 
Sem deixar de considerar que o filme possui relevantes traços autobiográficos, o que interessa a este estudo é propor um diálogo entre o trabalho do realizador iraniano e a autoetnografia. Autobiografia e autoetnografia são termos migrados dos estudos literários e contribuem de forma significativa para a compreensão da prática de Jafar Panahi. Se a autobiografia sempre foi considerada uma técnica de autorrepresentação, uma espécie de revelação da identidade singular daquele que narra as suas próprias histórias, autorrepresentação esta que, a partir do final do século vinte, começou a levar em conta a fragmentação e dispersão das identidades que constituem o próprio sujeito (Fischer, 1986), a autoetnografia oferece um passo adiante nesta discussão. Como bem assinalou Catherine Russell, "Autobiografia torna-se etnográfica no momento em que o cineasta ou videasta entende o seu ou a sua história pessoal imbricada num processo histórico e social mais amplo" 2 (Russell, 1999: 1). Como acontece nas narrativas fílmicas com este enfoque, as relações entre os diferentes espectros - político, institucional, social, pessoal - são as responsáveis por fazer com que um filme seja construído de uma maneira e não de outra. Além disso, algo inusitado ocorre com a criação de Táxi e é nele que encontra-se o maior interesse deste estudo: a explicitação dos mecanismos que compõem sua construção fílmica.

No filme em questão, Panahi conduz um táxi e, na medida em que os clientes vão utilizando os seus serviços, um mosaico da cidade de Teerão vai sendo configurado aos olhos dos espectadores. Com uma câmara subjetiva, do ponto de vista de quem encontra-se dentro de um veículo, com uma canção iraniana a tocar na rádio do carro, os três minutos e vinte segundos iniciais do filme mostram as ruas de Teerão: transeuntes e automóveis acompanhados por arranha-céus compartilham e justapõem suas existências na desordem típica de uma grande cidade. Portanto, logo na primeira cena, o realizador revela que, uma vez que o seu trabalho não possa estar desarticulado de sua história pessoal, nada melhor do que começar por contá-la a partir do ambiente em que está inserido, apropriando-se de um espaço público o qual é proibido ocupar.

Passados os minutos iniciais do filme, ainda parte do mesmo plano-sequência, o espaço urbano é, então, substituído pelo interior do carro no momento em que o primeiro cliente descobre uma câmara dentro do táxi e questiona se aquilo é um dispositivo antirroubo. A voz off do condutor responde afirmativamente à pergunta do cliente, explicitando que aquilo é uma espécie de dispositivo de segurança. Configura-se, pois, o diálogo entre as ruas e a preocupação com a segurança daquele que trabalha com um táxi numa grande

2. Livre tradução do original em inglês: "Autobiography becomes ethnographic at the point where the film - or videomaker - understands his or her personal history to be implicated in larger social formations and historical processes". 
cidade como Teerão, além da interlocução que se estabelece entre a realidade do realizador e o aparato fílmico. Em menos de quatro minutos, pois, Jafar Panahi evidencia as regras que farão parte da construção do seu filme, híbrido entre o que costumamos chamar por documentário - construção de uma figura que emerge da realidade e que a representa - e aquilo que é próprio da ficção - criação a partir de algo imaginado. É só depois de mostrar as cartas que serão utilizadas neste jogo que a imagem do realizador finalmente aparece, no segundo plano do filme, transcorridos nove minutos, a desempenhar o papel do condutor do táxi.

Não são raros, na história do cinema ficcional, os exemplos de realizadores que, ao interpretarem personagens com maior ou menor relevância para a narrativa, tornaram-se atores de si mesmos. Basta serem trazidos à baila os exemplos mais conhecidos, como é o caso das aparições de Alfred Hitchcock ou de François Truffaut em seus próprios filmes, ou ainda protagonismos como os de Guru Dutt em seu Kaagaz Ke Phool, de 1959. Por esse motivo talvez, uma primeira leitura possível ao observar Panahi como parte da narrativa de Taxi diz respeito ao fato dele estar a representar uma personagem ficcional no seu próprio filme, neste caso um taxista. Entretanto, passado menos de um minuto da aparição do realizador no ecrã, um dos seus clientes revela tê-lo reconhecido: "Sr. Panahi... Reconheci-o. Mesmo de boné, reconheci-o (...) Está fazendo um filme, Panahi? O homem e a mulher [personagens da primeira cena] eram atores, não eram?" ${ }^{3}$ (Panahi, 2015). Panahi, então, não esconde o sorriso orgulhoso de ter sido reconhecido por um transeunte. A personagem ficcional torna-se documental, o documentário autoetnográfico parece bater à porta de um espaço aparentemente ficcional, ou seja, a subjetividade do realizador investiga e transforma a realidade na mesma medida que a vida indaga e altera a trajetória de Panahi.

A explicitação das regras do jogo ainda no início do filme, faz com que o espectador mantenha um olhar atento às relações entre as diferentes personagens e entre elas e o seu entorno. Tal atenção compara-se ao que Bertolt Brecht propunha com o seu efeito de distanciação. Entretanto, se, com tal efeito, o encenador alemão tinha como objetivo tornar claro ao espectador que o mesmo se encontrava em frente a uma obra teatral e, por esse motivo, todos os elementos da encenação estavam cuidadosamente dispostos a ponto de fazer com que o espectador fosse capaz de criticar a história posta em cena, bem como a sua própria história (Brecht, 1978), Jafar Panahi organiza os elementos fílmicos de tal modo a criarem um estranhamento decorrente das inúmeras histórias que

3. Ao longo deste texto, aparecem inúmeras citações de trechos do filme. Todas elas foram traduzidas livremente a partir do francês do DVD distribuído por Mementos Films (2015). 
afloram a partir da colcha de retalhos construída pela justaposição dos tecidos do real e do ficcional. Ora, se as subjetividades são construídas a partir do contato com o outro, Panahi explicita que as histórias, as quais espectadores e cineastas elegem contar e/ou ouvir, são construídas em conjunto, não existindo, portanto, uma história verdadeira que contenha uma única versão acerca dos fatos.

Muito distante de colocar-se como vítima de um sistema conservador, $\mathrm{Pa}$ nahi apresenta-se como alguém que também faz parte de tais dinâmicas de poder, porque constituído por elas. Logo na primeira cena, por exemplo, existe o diálogo entre dois clientes desconhecidos que, eventualmente, dividiram o mesmo táxi em Teerão. O homem, sentado ao lado do condutor, ao notar a tal câmara de vigilância no táxi, comenta que um primo seu, ao sair de casa para o trabalho, deparou-se com o carro sem os quatro pneus. O homem então diz "Se mandasse neste país, enforcaria um ou dois para ver se acalmava o resto" (Panahi, 2015). A mulher sentada no assento de trás, indignada, contesta "Enforcá-los? E o que mais? Está indo um pouco longe. Talvez a pessoa em causa o tenha feito por necessidade" (Panahi, 2015). Inicia-se, então, uma longa discussão entre os dois que culmina na revelação da profissão de ambos: ela, professora, ele, especialista em assaltos. O homem, então, informa que não rouba os pobres e conclui que quem o faz merece a morte. Ora, esta vigilância exercida entre os pares, este julgamento e denúncia sem necessidade de intervenção do estado, estarão presentes em diferentes momentos do filme, dos quais os mais significativos identificam-se com o próprio realizador ou com a sua sobrinha, que na ausência de Panahi, ocupa o seu lugar.

$\mathrm{Na}$ tentativa de explicitar os poderes que atravessam não só a vida urbana de pessoas comuns, mas também a prática dos próprios artistas - grupo social que muitas vezes acredita estar afastado de tais linhas de força -, traz-se à baila as dinâmicas da cena seguinte, onde um comerciante, de nome Omid, aluga filmes proibidos de circularem no Irão. Omid revela que costumava entregar filmes para o filho do realizador e lembra-se que uma vez conseguiu dois diferentes títulos para o próprio Panahi: Era uma vez na Anatólia e Meia noite em Paris. Ao colocar Nuri Ceylan e Woody Allen no mesmo cesto de interesses, Panahi começa por desmontar a sua imagem como sendo a de um realizador que só possui referências enobrecedoras e coerentes.

Panahi, então, para o veículo e um cliente de Omid senta-se no assento de trás do táxi para negociar com o comerciante o aluguel dos filmes, enquanto Panahi observa em silêncio a negociação. No momento em que Omid tem que se ausentar para atender a uma chamada telefónica, o cliente revela a sua admiração por Panahi e, além disso, por ser ele estudante de cinema, pede 
ao realizador algumas dicas sobre como conseguir um bom tema para uma curta metragem. O estudante diz ainda que lhe custa acreditar que Panahi seja o sócio de Omid. O realizador responde ao aspirante a cineasta sobre a impossibilidade de ajudá-lo em relação ao tema para a curta metragem, pois tal caminho dever ser percorrido pelo jovem e por ninguém mais. Entretanto, silencia sobre a suposta sociedade entre ele e Omid e os dois despendem-se.

$\mathrm{Na}$ cena seguinte, Panahi, com muita delicadeza e firmeza, expulsa Omid de seu táxi e não cede ao pedido de desculpas do comerciante, nem a justificativa que o levou a mentir para o cliente - conseguiu vender o triplo do que normalmente vendia ao jovem e que juntos, Omid e Panahi, poderiam ter muitos lucros -, tampouco cedeu ao fato de Omid ter tentado convencê-lo que ambos eram ativistas culturais, já que sem Omid, nem o próprio Panahi poderia ter tido acesso a alguns dos filmes que o comerciante havia conseguido no passado. Fica evidente, pois, que Panahi não identifica-se com Omid e, em consequência, expulsa-o do seu espaço cinematográfico, ao retirá-lo do enquadramento da lente da sua câmara, tornando-se evidente a hierarquização das funções desempenhadas por cada um deles em tal empreitada. Panahi, anteriormente silenciado pelo governo, transgride a ordem judicial para fazer um filme, mas é ele quem silencia Omid, dentro de um espaço onde quem dita as regras é o argumentista, o realizador e o montador, funções estas exercidas por Panahi em Táxi.

À metade do filme, ao encontrar um antigo vizinho, Arash, que não via há seis anos, Panahi assombra-se ao tomar conhecimento que o ex-vizinho havia sido assaltado em sua própria casa e que, embora tivesse reconhecido os assaltantes, não os tinha denunciado. Arash justifica o seu silêncio pelo fato do episódio em sua casa ter ocorrido logo após noticiarem o enforcamento de outros criminosos - possivelmente os mesmos que haviam sido referenciados pelo especialista em assalto no início do filme. Por serem conhecidos seus e ele saber que passavam por dificuldades financeiras, não teve coragem de denunciá-los, optando por silenciar e, de certa forma, por ajudar os dois a superarem a situação financeira desastrosa que enfrentavam. Aparentemente, o antigo vizinho queria apenas desabafar, sabia que Panahi estava proibido de filmar, mas desejava que algum outro realizador fizesse um filme com a sua história. No desfecho da cena, um funcionário do café da esquina traz sumos de laranja para os dois homens que permanecem dentro do carro. O rosto do jovem é coberto pelo enquadramento da janela do carro e pelo posicionamento do dispositivo fílmico. Quando o funcionário vira de costas e se afasta do táxi, Arash revela que aquele era o assaltante. Panahi ainda tenta virar a câmara em direção ao rapaz, mas ele já está muito afastado e não é possível reconhecer o 
seu rosto. O realizador torna-se ainda mais perplexo e pergunta a Arash o motivo dele não ter avisado antes que aquele era o assaltante, negando a chance do realizador registar a imagem do agressor. Arash limita-se a responder que o assaltante "parece-se consigo, comigo, com qualquer um que esteja à nossa volta" (Panahi, 2015). Claro está, com tal sequência, que aquilo que se é capaz de atacar é sempre mais forte que nós mesmos, uma vez que somos constituídos pelo que desejamos combater. Jafar Panahi é o realizador que tem sido punido pelo seu trabalho politicamente contestador, mas ele também, assim como todos nós, está submetido às mesmas regras que regem a manifestação hostil do especialista em assaltos da primeira cena.

Finalmente, vale destacar a relação de Panahi com a sobrinha, Hana, que inicia-se quando o realizador vai buscar a miúda à escola, mas chega com uma hora de atraso. Hana tem cerca de dez anos e está muito irritada e decepcionada com Panahi. Depois de acalmar-se, Hana saca uma câmara de dentro da mochila e começa a filmar o tio. Ela informa que a professora de cinema estipulou um prazo de um mês para que os alunos fizessem uma curta metragem e que, portanto, ela filmaria os conselhos importantes que o tio poderia dar a esse respeito. Aqui, o realizador escancara a sua condição de sujeito de análise do próprio filme. Se, em grande parte da produção documental, estamos acostumados com a figura do realizador que entrevista as personagens de seu filme, ou então, nos documentários autobiográficos em que a narração seja feita em primeira pessoa, em Táxi, Jafar Panahi assume ainda um outro papel, o de ser entrevistado pelos demais. A este respeito, Russell afirma que, para além da voz over do cineasta, existem também outras duas funções desempenhadas pelo realizador nos filmes autoetnográficos: o papel daquele que observa e daquele que é observado (Russell, 1999). Esta terceira função, a de ser percebido pelos próprios personagens da sua história, tem o seu exemplo mais contundente na câmara da sobrinha direcionada para o rosto do realizador. Entretanto, ao longo do filme, tem-se a reiteração da evocação desta condição, quando outras personagens assumem o papel de entrevistadores de Panahi. Tal é o caso do especialista em assaltos, do comerciante de filmes proibidos, da mulher do homem acidentado, do aspirante a realizador e da advogada de defesa.

Com o passar do tempo, Hana regista não apenas a imagem do tio, mas também a paisagem e as outras personagens do enredo. Tal fato não parece incomodar Panahi que, de forma silenciosa, autoriza que a sobrinha compartilhe a realização de Táxi com ele. Num determinado momento do filme, por exemplo, Panahi para o carro e deixa Hana sozinha por algum tempo, pois precisa fazer algo que não sabemos o que é. A sobrinha aproveita para filmar um casal de noivos a serem registados pela lente de uma outra câmara, a de 
um fotógrafo de casamentos. Um miúdo que está a recolher objetos das latas de lixo na rua, ao passar pelo casal percebe que uma cédula de dinheiro caiu do bolso do noivo e guarda-a para si. Hana, em nome da criação de um filme passível de distribuição, chama o miúdo e diz a ele, em tom autoritário, que deve devolver o dinheiro para o noivo, caso contrário, ela não poderá utilizar as filmagens que acabara de fazer, já que o fato de haver um furto explícito tornaria a cena, segundo às regras estipuladas pela escola, pertencente a um filme não distribuível, a saber: "qualquer situação aparentemente problemática suscetível de ser censurado por aquele que realiza o filme" (Panahi, 2015). Portanto, em nome de um filme sobre altruísmo e sacrifício - palavras da própria realizadora mirim -, Hana oferece dez vezes menos a quantia encontrada pelo miúdo, para que ele devolva o dinheiro ao noivo. Certamente, o jovem não devolve e é o fim de mais uma ideia para a curta metragem da escola.

$\mathrm{Se}$, numa primeira leitura, a cena pode ser analisada como sendo um alerta sobre a dormência e o autoritarismo dos jovens realizadores que seguem as regras fílmicas ensinadas pela instituição governamental, por outro pode-se também pensar que a cena é um aviso direcionado também aos realizadores que supostamente vão de encontro a estas regras, como é o caso do próprio Panahi. Ora, ele afastou-se da cena para ir sabe-se lá onde, deixando a sobrinha com um dispositivo fílmico na mão, uma paisagem urbana e personagens à sua disposição, típica atitude de um mestre que observa ao longe as ferramentas que o seu discípulo já consegue dominar. De que maneira, pois, Panahi, ao desempenhar o papel de realizador, consegue estar liberto das questões que são próprias à sua prática?

As ordens do discurso, como bem assinala Michel Foucault, transitam entre três interdições que se cruzam e se reforçam: "o tabu do objeto, o ritual da circunstância e o direito privilegiado ou exclusivo do sujeito que fala". (Foucault, 1970: 9). Táxi escancara estas três dimensões, auxiliando no processo de compreensão dos mecanismos que estão em jogo nos poderes atuantes, não apenas na instituição governamental do Irão, mas também naquelas presentes no fazer fílmico, onde o realizador ocupa uma das posições de maior prestígio. Se por um lado tem-se o tabu do objeto como sendo a proibição judicial recaída sobre a realização de Panahi e o ritual da circunstância como sendo as regras próprias do fazer cinematográfico, então, como terceira interdição encontra-se a voz privilegiada do próprio realizador. Portanto, um dos maiores contributos de Jafar Panahi é o de questionar estas três formas de proibição, mesmo se, para tal empreitada, tenha sido necessário propor o desmoronamento do seu próprio ato de realização. Dessa maneira, o realizador, assim como qualquer um de nós, não está ileso de compactuar com os poderes, mas tal fato em 
nada diminui a importância do seu trabalho e da sua resistência, até porque, ao colocar-se na berlinda, Panahi torna visível e problematiza o que parece estar escondido.

Se os meios de comunicação insistem em dizer que a censura tem proibido Panahi de fazer filmes, este estudo salienta uma ideia diametralmente oposta a esta: para fazer este filme, Panahi precisou da censura e acrescentou a ela o diálogo com a sua cidade e com os seus habitantes. Os acontecimentos da vida de Panahi estão, a todo momento, a cruzar com a história ficcional criada por ele, mas também, por sua vez, a ficção criada por ele faz lembrar, constantemente, que as decisões de um realizador também são capazes de reverberar em mundos fora do ecrã.

\section{Referências bibliográficas}

Fischer, M. (1986). Ethnicity and the Post-Modern Arts of Memory. Writing Culture: the poetics and politics of Ethnography. Berkeley: University of California.

Brecht, B. (1978). Estudos sobre teatro. Rio de Janeiro: Nova Fronteira.

Foucault, M. (1999). A Ordem do Discurso. São Paulo: Edições Loyola.

Russell, C. (1999). Autoethnography: Journeys of the Self Author. Experimental Ethnography. Durham: Duke University Press.

\section{Filmografia}

Taxi Teheran (2015), de Jafar Panahi.

This is not a film (2015), de Jafar Panahi. 